\title{
The Art of Improvising: The Be-Bop Language and the Major Seventh Chords
}

\section{Carmine Cataldo}

Jazz Pianist and Composer, $\mathrm{PhD}$ in Mechanical Engineering, Battipaglia, SA, Italy

Email: catcataldo@hotmail.it

How to cite this paper: Cataldo, C. (2017). The Art of Improvising: The Be-Bop Language and the Major Seventh Chords. Art and Design Review, 5, 222-229. https://doi.org/10.4236/adr.2017.54018

Received: September 19, 2017

Accepted: October 16, 2017

Published: October 19, 2017

Copyright (C) 2017 by author and Scientific Research Publishing Inc. This work is licensed under the Creative Commons Attribution International License (CC BY 4.0).

http://creativecommons.org/licenses/by/4.0/

\begin{abstract}
This article represents the third part of a simple and intuitive method, finalized to "speaking", almost immediately, the Be-Bop language, without possessing any particular jazz background. We herein exclusively discuss the improvisation techniques regarding the Major Seventh Chords. Starting from a specific extended "sentence", built around the Major Triad, we show how we can instantly deduce further sentences, how to modify them, by cutting and adding "words", and how to effectively combine them. Moreover, we briefly explain how to deal with Tonicizations and ordinary Jazz Turnarounds.
\end{abstract}

\section{Keywords}

Jazz Improvisation, Be-Bop, Fast Learning, Triads, Major Seventh Chords

\section{Introduction}

We herein exclusively deal with the major seventh chord, starting from a fundamental extended "sentence", built around the major triad, which immediately gives birth to three further sentences. The sentences so obtained can be easily cut, modified, by using new "words" (Wise, 1983) and extensions, and then combined. As elsewhere discussed (Cataldo, 2017a, 2017b), the peculiarity of the method lies fundamentally in the fact that the attention of the improviser is focused on triads.

\section{The Method}

\subsection{The Fundamental "Sentence"}

We here in will deal with a Cmaj7 chord. Obviously, the method should be practiced and mastered in all 12 keys.

Although it is anything but a novelty (Wise, 1983), we will carry out the whole 
discussion in terms of sentences and words.

Before starting, it is worth underlining how the only required background consists in the mere knowledge of triads.

The fundamental sentence we have to start from is shown in following Staff:

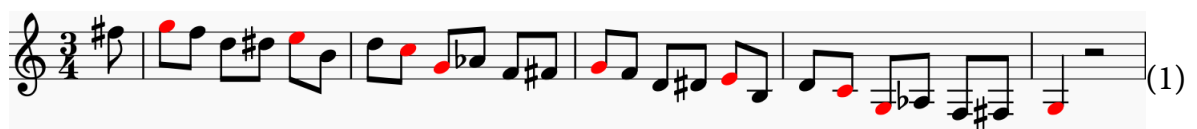

In Staff (1), like in all the staves in this paper, the chordal notes (meant as the notes that constitute the triad) are highlighted in red.

The particular time signature (3/4) in Staff (1), chosen exclusively for the sake of convenience, is related to the "odd periodicity" of the sentence. On this subject, it is worth underlining how the sentence in question could have been equivalently written in $6 / 4$ time, so as to emphasize its periodic behavior.

\subsection{Learning to "See" the Major Triad}

The fundamental sentence can be evidently played starting from each of the chordal notes, by means of a simple translation.

It is essential to underline that, in playing both the sentence we have just examined and the ones that will arise from it, the musician must focus his/her at tention "exclusively" on the major triad and its inversions (in case of translation).

From the pattern shown in Staff (1), exploiting the translation and carrying out a banal cutting, we immediately deduce the three following sentences:
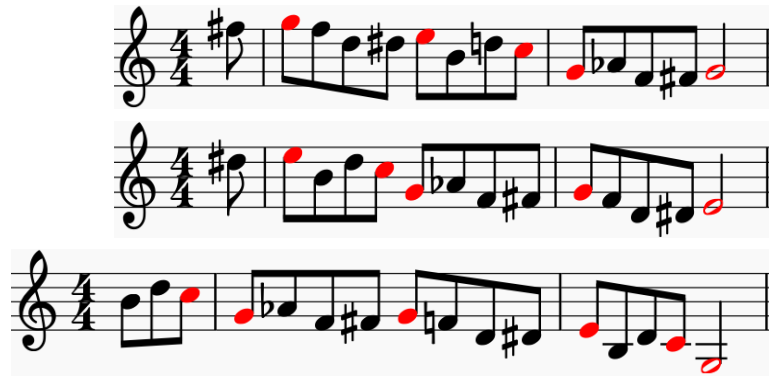

All the anacruses are clearly optional.

Although the topic is not herein properly addressed, we highlight how the sentences in Staves (2), (3), and (4) lend themselves to several metric displacements.

At this point, it is worth practicing the following exercise based upon the major triad and the ascending (chromatic) approach

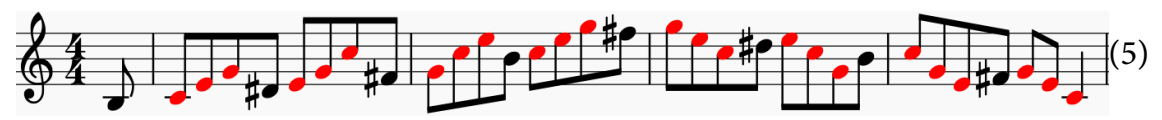

By means of a simple metric displacement, from the previous exercise, we can deduce the following:

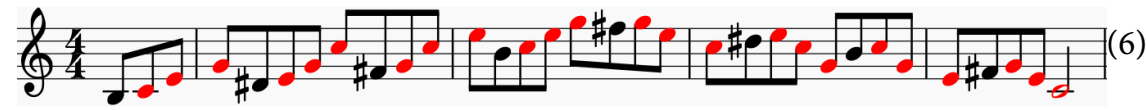


From Staves (2), (3), and (4), the latter considered with a metric displacement, exploiting the previous exercise we deduce the three following sentences:

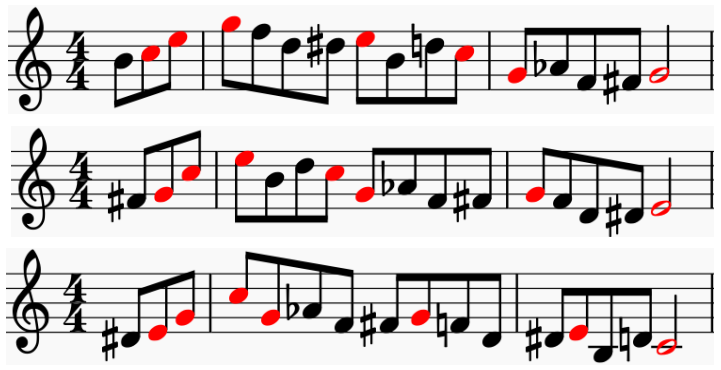

At this point, we can already start to combine the sentences deduced, so as to obtain something more complex (Baker, 1988a, 1988b, 1988c, 1988d; Wise, 1983).

For example, from Staves (6) and (8), the latter extended as shown in Staff (1), we can easily deduce the underlying long sentence:

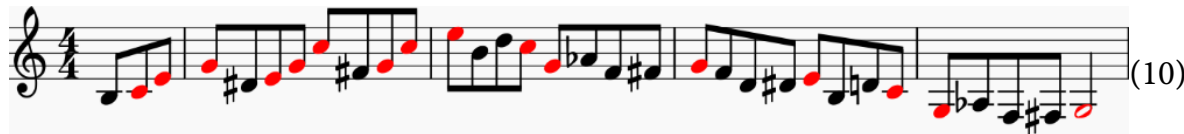

Let's now practice the following pattern based upon the mixed approach concept:

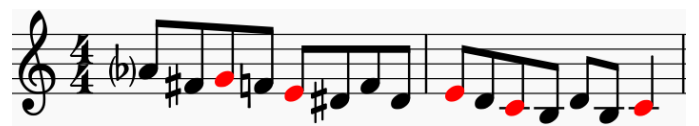

The previous sentence allows the musician to sound very "chromatic".

Obviously, coherently with what highlighted at the beginning of this section, in performing the exercise in Staff (11), the improviser must focus his/her attention "exclusively" on the major triad.

We can clearly continue to mix the sentences, now with an additional ingredient.

For example, from Staff (3), extended as shown in Staff (1), and Staff (11), transposed an octave higher, we obtain:

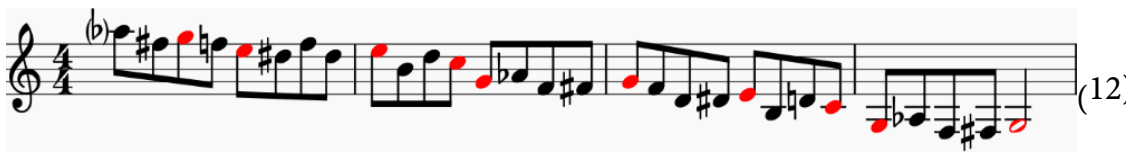

Let's now consider the following new "word" based upon the mixed approach concept like the one in Staff (11), but built, in this case, considering an ascending motion:

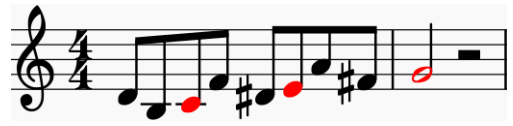

Exploiting the word just considered, we can obtain a great deal of new sentences.

For example, from Staff (2), transposed an octave lower and stopped at the fifth, Staff (11), and Staff (13), we obtain: 


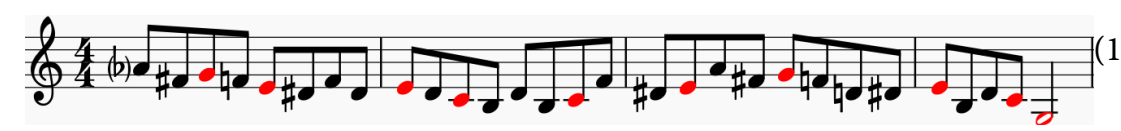

Let's now consider another new "word", nothing but a very short "back and forth" chromatic bridge between the fifth and the (major) sixth:

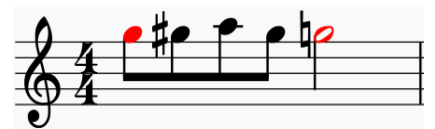

From Staff (7), considered without the anacrusis and stopped at the fifth, by exploiting the new word just obtained, we deduce the following sentence:

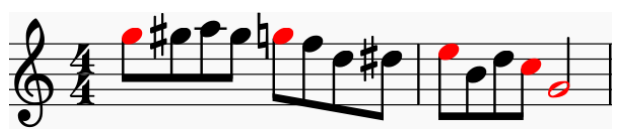

The previous sentence allows us to modify the fundamental one. In the following Staff an alternative version of the fundamental sentence, now with an "even periodicity", is shown.

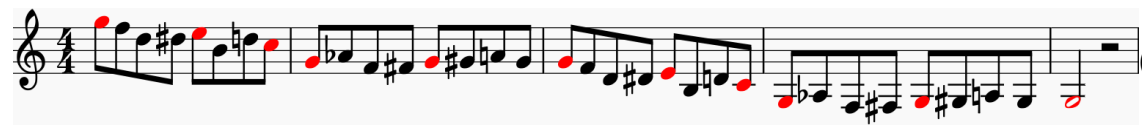

Following a line of reasoning that at this point should be clear, the sentence in Staff (17) can be exploited in order to deduce a great deal of further sentences.

\subsection{Introducing the (Major) Seventh}

Let's consider the following new word, that simply consists in a descending chromatic bridge between the major seventh (depicted in green) and the fifth:

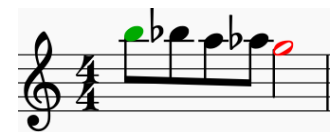

From Staves (2) and (18), the first considered without the anacrusis and stopped at the fifth, we immediately obtain:



If we consider the "back and forth" version of the chromatic bridge in Staff (18), from Staff (19) we obtain a new long sentence extended along two consecutive octaves. This sentence, shown in the underlying Staff, gives birth to three further sentences, omitted for brevity, that can be progressively modified in the usual way.

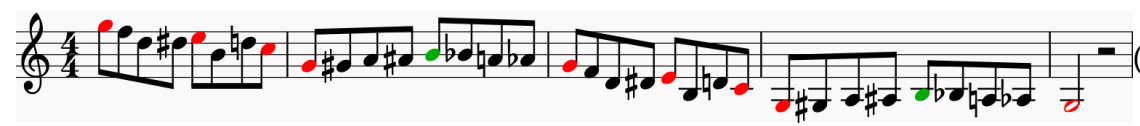

From Staff (14), by carrying out a simple cutting and exploiting the "back and forth" chromatic bridge between the fifth and the seventh, we have:

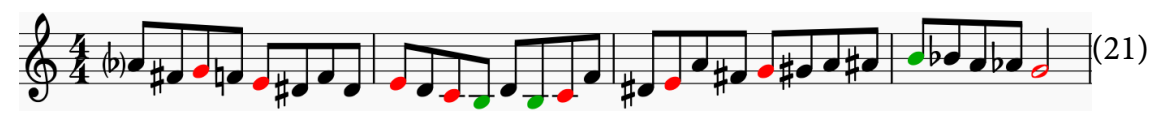


From Staff (13), exploiting the sentence shown in Staff (20), we obtain:

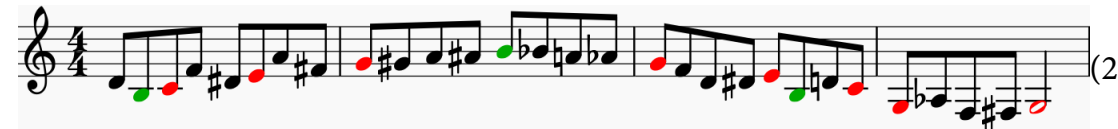

From Staff (16) exploiting, once again, the sentence shown in Staff (20), we have:

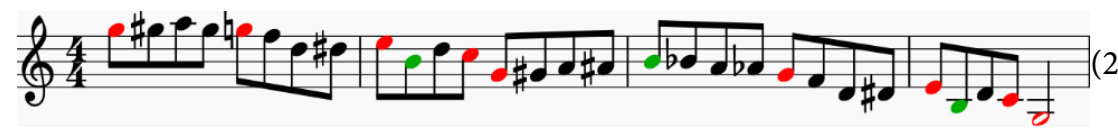

\subsection{Introducing the Ninth}

Let's now consider the two following new words, extremely similar to each other, that simply consist in a descending chromatic bridge between the ninth and the major seventh, both depicted in green:

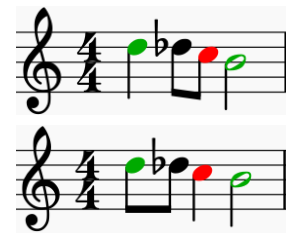

Obviously, the second of the above-mentioned words simply emphasizes the root. Exploiting Staff (18), from Staves (24) and (25) we obtain, respectively, the two following short sentences:

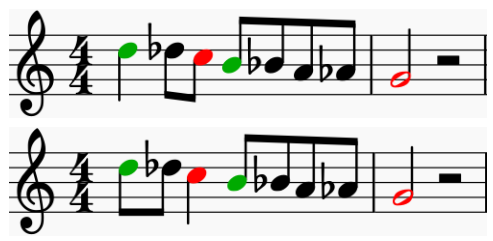

At this point, it is very easy to obtain a multitude of new sentences, whose length and complexity basically depend on the capability of cutting and combining.

For example, from Staves (19) and (27), the first transposed an octave lower and stopped at the fifth, we immediately obtain the following short sentence:

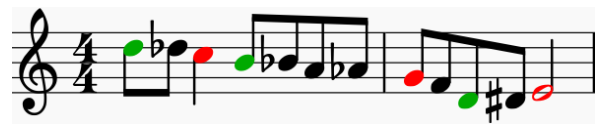

Just to provide a further example, from Staves (17) and (28), exploiting the "back and forth" chromatic bridge between the fifth and the seventh, we easily obtain:

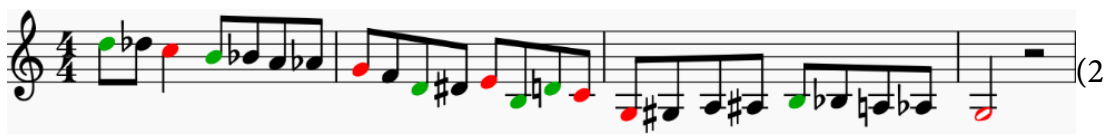

It is worth highlighting how the sentence in Staff (28) can be slightly modified as follows (Garland, 1999; Kelly, 2013; Parker, 1978; Powell, 1998, 2002):

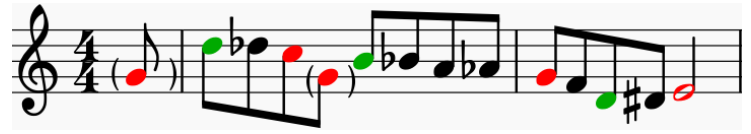


Bearing in mind that, according to the so-called diatonic substitutions (D'Errico, 2017), each majors seventh chord can be replaced by the minor seventh one "placed" a major third higher (and by the minor seventh one "placed" a minor third lower), we can now consider the following extremely simple new word:

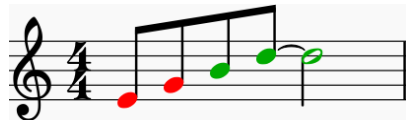

From Staves (30) and (31), we deduce the following interesting Be-Bop "loop":



From the loop shown in Staff (32), by means of simple translations, we instantly obtain the following four sentences:

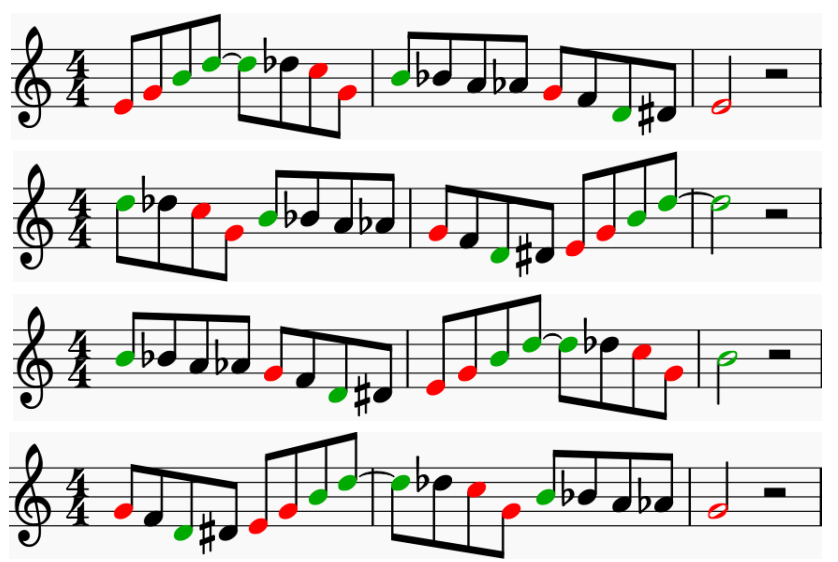

\subsection{Tonicizations and Turnarounds}

The major seventh chords can be tonicized (D'Errico, 2017; Dobbins, 2010; Levine, 2009). The procedure is practically indispensable when the chord remains the same for a certain number of bars.

For example, Cmaj7 can be followed and/or preceded by $G 7$, sometimes considered with the flat ninth, so as to legitimize a "diminished substitution" (Parker, 1978).

One of the strong points of the method consists in the fact that all the sentences we have deduced (and all the ones that may be further deduced by following the line of reasoning herein exploited) are perfectly suitable for tonicized major chords, no matter where the tonicization actually takes place, and ordinary turnarounds.

If we consider, for example, the sentence in Staff (2), we easily realize how it can be played on the following progressions: [Cmaj7|G7|Cmaj7], [Cmaj7|D-7 G7|Cmaj7], [Cmaj7 A-7|D-7 G7|Cmaj7].

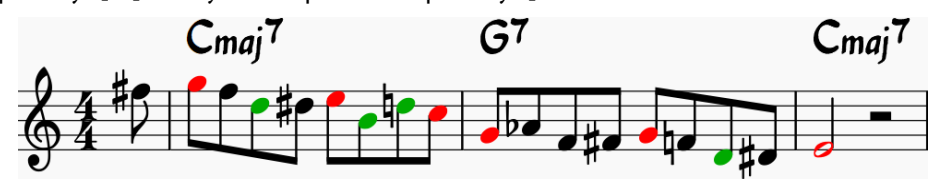




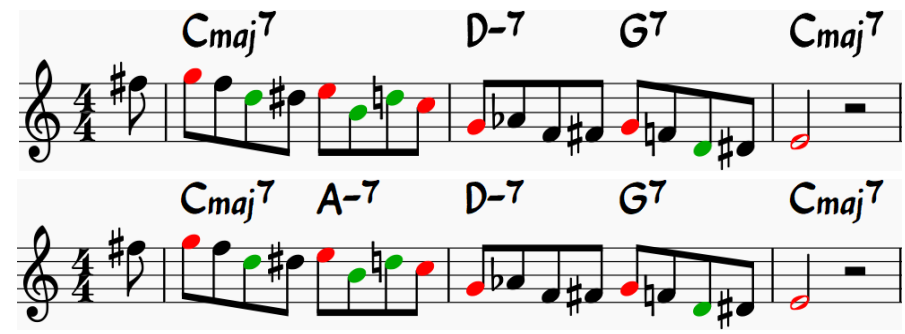

Similarly, if we examine the sentence in Staff (33), we easily realize how it can be played on the same harmonic progressions we have just considered:

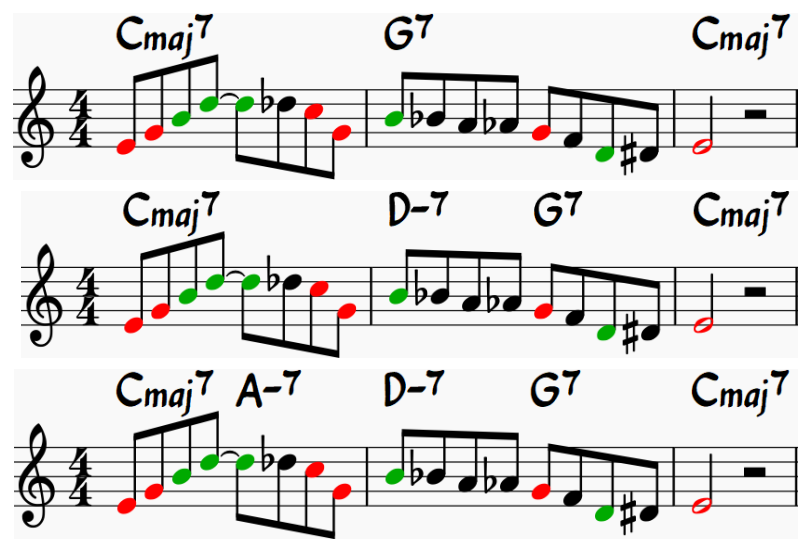

For the sake of brevity, the suitability of the sentences in case of harmonic substitutions, such as the secondary dominant ones, is not herein addressed.

\section{Brief Conclusion}

As elsewhere underlined (Cataldo, 2017a, 2017b), this method constitutes nothing but a simplified introduction to the Be-Bop language. Nonetheless, all the sentences herein deduced, net of possible "enrichments" (Cataldo, 2017a) and combinations with "public domain" patterns (Coker et al., 1982; Nelson, 2010), can be easily found by examining well-known solo transcriptions (Garland, 1999; Kelly, 2013; Parker, 1978; Powell, 1998, 2002).

The fundamental peculiarity of the method, once again, consists in the fact that the attention of the improviser, whose jazz background can be very minimal, is fundamentally focused on triads: basically, there is no need to have any further knowledge in order to start playing Be-Bop. Suffice it to consider that, in introducing the seventh and the ninth, the improviser can also refer to the major triad placed a perfect fifth higher (with respect to the root of the chord on which he/she is improvising).

Obviously, the knowledge of harmony and the capability of mastering several effective scales (hexatonic, such as the whole-tone scale, heptatonic, such as the super-Locrian, octatonic, such as the halftone-tone), as well as very popular patterns, allow the musician, beyond any doubt, to further enrich his/her language and, above all, to play with reasonable consciousness (D’Errico, 2015).

\section{Acknowledgements}

This paper is dedicated to my father, Antonio Cataldo, who unexpectedly passed 
away on the 11 th of June 2016.

I would like to thank my friends Francesco D'Errico, Giulio Martino, and Sandro Deidda, excellent Italian jazz musicians and esteemed teachers at the Conservatory of Salerno, for their precious suggestions.

\section{References}

Baker, D. (1988a). How to Play Bebop (Volume 1). Los Angeles, CA: Alfred Publishing Co. Inc.

Baker, D. (1988b). How to Play Bebop (Volume 2). Los Angeles, CA: Alfred Publishing Co. Inc.

Baker, D. (1988c). How to Play Bebop (Volume 3). Los Angeles, CA: Alfred Publishing Co. Inc.

Baker, D. (1988d). Jazz Improvisation. Los Angeles, CA: Alfred Publishing Co. Inc.

Cataldo, C. (2017a). The Art of Improvising: The Be-Bop Language and the Dominant Seventh Chords. Art and Design Review, 5, 181-188. https://doi.org/10.4236/adr.2017.53014

Cataldo, C. (2017b). The Art of Improvising: The Be-Bop Language and the Minor Seventh Chords. Art and Design Review, 5, 213-221.

https://doi.org/10.4236/adr.2017.54017

Coker, J., Casale, J., \& Campbell, G. (1982). Patterns for Jazz-A Theory Text for Jazz Composition and Improvisation. Los Angeles, CA: Alfred Publishing Co. Inc.

D’Errico, F. (2015). Fuor di Metafora-Sette Osservazioni sulP Improvvisazione Musicale. Naples, Italy: Editoriale Scientifica.

D’Errico, F. (2017). Armonia Funzionale e Modalità-Rudimenti per I Improvvisazione a Indirizzo Jazzistico. Naples, Italy: Editoriale Scientifica.

Dobbins, B. (2010). Jazz Arranging and Composing-L'Approccio Lineare (Italian Edition by Roberto Spadoni). Italy: Volontè \& Co.

Garland, R. (1999). The Jazz Piano Solos of Red Garland (by Tony Genge). Houston, TX: Houston Publishing.

Kelly, W. (2013). The Wynton Kelly Collection: 25 Solo Transcriptions (by Michael Miller). New Albany, IN: Jamey Aebersold Jazz.

Levine, M. (2009). The Jazz Theory Book (Italian Edition by F. Jegher). Milan: Curci Jazz.

Nelson, O. (2010). Patterns for Improvisation. New Albany: INJamey Aebersold Jazz.

Parker, C. (1978). Charlie Parker Omnibook. Los Angeles, CA: Atlantic Music Corporation.

Powell, B. (1998). Bud Powell Classics (Artist Transcriptions). Milwaukee, WI: Hal Leonard.

Powell, B. (2002). The Bud Powell Collection: Piano Transcriptions (Artist Transcriptions). Milwaukee, WI: Hal Leonard.

Wise, L. (1983). Bebop Bible the Musicians Dictionary of Melodic Lines. REH Publications (Distributed by Columbia Pictures Publications). 